\title{
Inhibition of the $\alpha$-Glucosidase Specific for Collagen Disaccharide Units in Diabetic Rat Kidney by in Vivo Glucose Levels: Possible Contribution to Basement Membrane Thickening
}

\author{
M.Sternberg ${ }^{1}$, J. Andre ${ }^{1}$ and J. Peyroux ${ }^{2}$ \\ ${ }^{1}$ Département de Biochimie, Faculté de Médecine Broussais-Hôtel-Dieu and ${ }^{2}$ Laboratoire de Pharmacologie, Faculté de Pharmacie, Paris, \\ France
}

\begin{abstract}
Summary. The activity of the $\alpha$-glucosidase specific for collagen disaccharide units has been measured in kidney cortex homogenates of streptozotocin-diabetic rats under three different conditions: (1) in dialyzed homogenates; (2) in non-dialyzed homogenates; (3) in non-dialyzed homogenates to which glucose was added to compensate for dilution due to homogenization and to reach the glucose concentration determined in kidney cortex $(37.5 \pm 2.8 \mathrm{mmol} / \mathrm{kg}$ diabetic cortex versus $6.8 \pm 0.3 \mathrm{mmol} / \mathrm{kg}$ normal cortex). Under the latter condition, the enzyme activity was markedly decreased in diabetic kidney cortex when compared with that of normal agematched controls: $4.03 \pm 0.25$ versus $6.82 \pm 0.29$ units $/ \mathrm{mg}$ pro-
\end{abstract}

tein $(p<0.001)$. Inhibition of enzyme activity was also significant in non-dialyzed diabetic homogenates without additional glucose. In the absence of glucose (in the dialyzed homogenates), it is confirmed that the enzyme activity is elevated in diabetic kidney. The glucose inhibition of the enzyme activity has been shown to be important under in vivo conditions. It may therefore contribute to kidney basement membrane thickening.

Key words: $\alpha$-Glucosidase, rat, basement membrane thickening, collagen disaccharide units, streptozotocin-diabetes, glucose inhibition, kidney.
With long-term streptozotocin diabetic rats, we have observed previously an increased activity of the $\alpha$-glucosidase specific for collagen disaccharide units (glucosylgalactosyl-hydroxylysine glucohydrolase) in the dialyzed kidney cortex homogenate and supernatant $[1,2]$. In the same animals, we have confirmed the presence of kidney glomerular basement thickening [2]. Basement membrane collagen is known to be rich in disaccharide units [3] and the proportion of these may be elevated in diabetes [4-6]. The increased enzyme activity of the dialyzed (glucose-free) fractions appears to be related to elevated enzyme concentration in the kidney, possibly induced by raised substrate levels. On the other hand, we have shown competitive inhibition of the enzyme activity by glucose, a product of the reaction with inhibition constant $\mathrm{Kp}=7.5 \times 10^{-3} \mathrm{~mol} / 1$ [7].

Since glucose freely penetrates the kidney cells [8], it was of interest to measure the enzyme activity in diabetic kidney cortex without dialysis, in the presence of glucose levels found in vivo. For this purpose, it was necessary to evaluate the glucose concentration in kidney cortex. The enzyme activity was then determined under three conditions: (1) in dialyzed kidney cortex homogenates; (2) in non-dialyzed kidney cortex homogenates;
(3) in non-dialyzed homogenates with added glucose to compensate for dilution due to homogenization.

Significant inhibition of enzyme activity under conditions found in vivo could contribute to basement membrane thickening since this enzyme is believed to be involved in the catabolism of basement membrane collagen [1].

\section{Materials and Methods}

\section{Diabetic Rats}

Forty male Wistar rats were divided in random order into two groups: one group (weight $231 \pm 12 \mathrm{~g}$, mean $\pm \mathrm{SD}$ ) was injected iv. with streptozotocin (Sigma, St Louis, Missouri, USA, $55 \mathrm{mg} / \mathrm{kg}$ body weight) in $\mathrm{NaCl}(100 \mathrm{mmol} / \mathrm{l}) /$ citrate buffer $(1 \mathrm{mmol} / 1), \mathrm{pH} 4.5$. The agematched control group (mean weight $223 \pm 14 \mathrm{~g}$ ) was injected with buffer alone. Animals were housed five to a cage and allowed free access to food (standard pelleted rat chow A 103, UAR Co, Villemoisson, France) and water. Arterial pressure was estimated weekly by the tail cuff method. Blood was taken from the orbital sinus in non-fasting animals for glucose determination every month. The mortality rate of the diabetic rats before sacrifice was $14 \%$ (versus $5 \%$ in the controls). Ten diabetic and ten control rats were randomly chosen for the experiment. These rats were sacrified 33 weeks after streptozotocin in- 


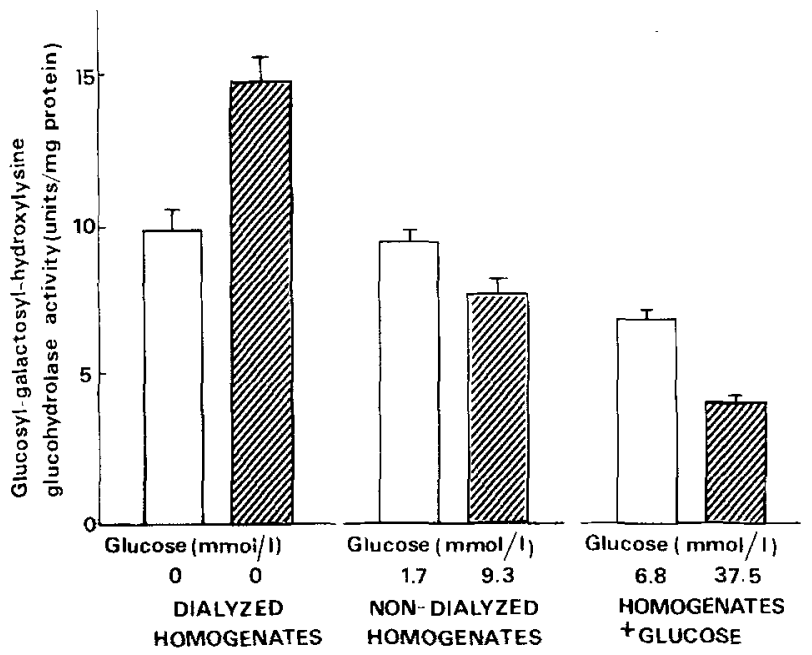

Fig. 1. Glucosyl-galactosyl-hydroxylysine glucohydrolase specific activity in kidney cortex homogenates from diabetic (ש) and control ( $\square$ ) rats in the presence or absence of glucose. "Homogenates + glucose' refers to non-dialyzed homogenates with glucose added to simulate the in vivo level. Values are mean $\pm \operatorname{SEM}(n=10)$. Significant differences were observed between diabetic and control rats in dialyzed homogenates $(p<0.001)$, in non-dialyzed homogenates $(p<0.01)$ and in homogenates + glucose $(p<0.001)$
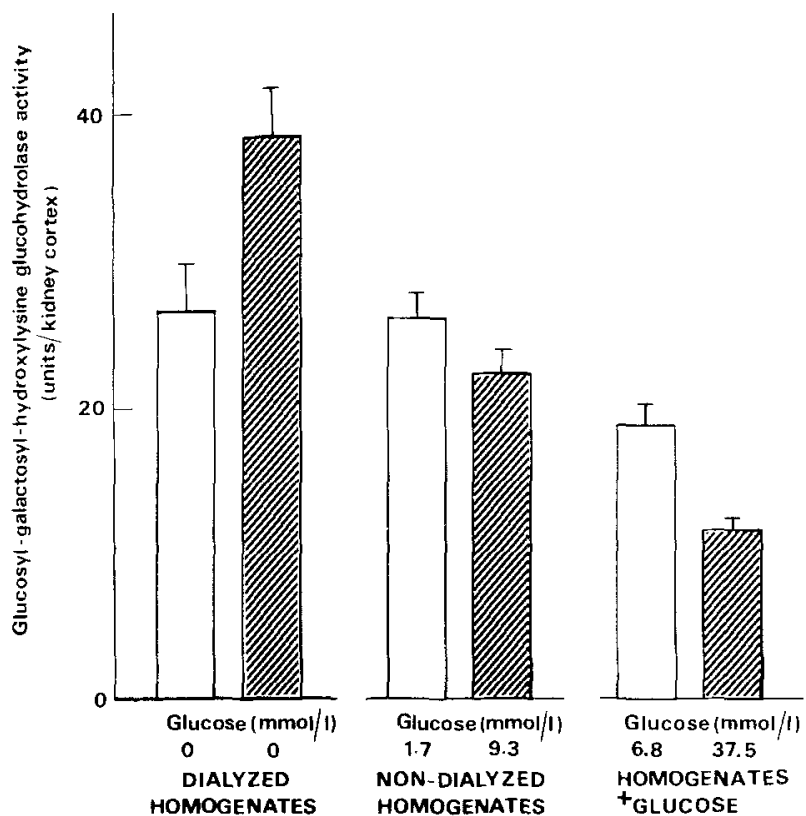

Fig. 2. Glucosyl-galactosyl-hydroxylysine glucohydrolase total activity in kidney cortex from diabetic ( $\mathbb{Z}$ ) and control $(\square)$ rats as measured in the presence or absence of glucose. 'Homogenates + glucose' refers to non-dialyzed homogenates with glucose added to simulate the in vivo level. Values are mean $\pm \operatorname{SEM}(n=10)$. Significant differences were observed between diabetic and control rats in dialyzed homogenates $(p<0.05)$ and in non-dialyzed homogenates + glucose $(p<0.001)$

jection. One day before sacrifice they were put in metabolic cages ( $\mathrm{Pa}$ jon, Orléans, France) with water ad libitum for $24 \mathrm{~h}$ urine collection. Some hours later and after feeding, blood was taken from the abdominal aorta under ether anaesthesia. The kidneys were removed and frozen in liquid nitrogen $\left(-196^{\circ} \mathrm{C}\right)$ until used. Diabetic and control rats were sacrified alternately.

\section{Enzymatic Determinations}

Kidney homogenates: Frozen cortices were put on ice, dissected and homogenized with a Potter homogenizer in three volumes of cold $\mathrm{NaCl}(125 \mathrm{mmol} / \mathrm{l})$ phosphate buffer $(25 \mathrm{mmol} / 1), \mathrm{pH} 7.0$. Glucose concentration was measured in the homogenate and the concentration in the kidney cortex calculated after dilution correction. The homogenate was divided into three parts: one was dialyzed against cold $\mathrm{NaCl}(125 \mathrm{mmol} / \mathrm{l})$ phosphate buffer $(25 \mathrm{mmol} / \mathrm{l}) \mathrm{pH} 7.0$; the second was kept on ice undialyzed; glucose was added to the third, non-dialyzed, part to simulate the calculated glucose concentration in the kidney cortex before dilution.

Substrate and product: The substrate Glucosyl-galactosyl-hydroxylysine (Glc-Gal-Hyl) was prepared from bovine kidney cortex basement membranes as described in (1). The product Galactosyl-hydroxylysine (Gal-Hyl) was prepared by mild acid hydrolysis of GlcGal-Hyl. The substrate and the product were radio-labelled by treatment with galactose-oxydase followed by reduction with tritiated potassium borohydride $[1,3]$. The specific activity obtained was $12.7 \mathrm{CV} /$ mol for Glc- $\left[{ }^{3} \mathrm{H}\right] \mathrm{Gal}-\mathrm{Hyl}$ and $43 \mathrm{Ci} / \mathrm{mol}$ for $\left[{ }^{3} \mathrm{H}\right] \mathrm{Gal}-\mathrm{Hyl}$.

Assay for Glc-Gal-Hyl glucohydrolase activity in the presence of glucose: This was effected by a modification of the procedure described previously [7]. Briefly, Glc- $\left.\left.\right|^{3} \mathrm{H}\right] \mathrm{Gal}-\mathrm{Hyl}(43 \mathrm{nCi}, 12.7 \mathrm{Ci} / \mathrm{mol})$ was dried with unlabelled Glc-Gal-Hyl (185 nmol) in small glass tubes and dissolved in $1 \mathrm{~mol} / \mathrm{l}$ sodium phosphate buffer $(20 \mathrm{ul}), \mathrm{pH} 4.4$. The kidney enzyme $(100 \mu)$ was added and the mixture incubated for $1 \mathrm{~h}$ at $37^{\circ} \mathrm{C}$. Substrate and product were separated by high voltage paper electrophoresis. After scanning with a radiochromatogram scanner (Packard, La Grange, Illinois, USA) $0.5 \mathrm{~cm}$ wide bands, corresponding to the peaks of radioactivity, were eluted with $2 \mathrm{ml}$ distilled water. The radioactivity was determined in a Packard Tri-Carb liquid scintillation spectrometer; the $\left[{ }^{3} \mathrm{H}\right] \mathrm{Gal}-\mathrm{Hyl}$ peak was measured and the total amount of Gal-Hyl released calculated after efficiency correction. The mean difference between duplicate results was $5 \%$. Under these assay conditions product release has been shown to be proportional to the enzyme concentration. One unit of enzyme activity corresponds to $1 \mathrm{nmol}$ of Gal-Hyl released per h at $37^{\circ} \mathrm{C}$.

\section{Chemical Determinations}

Blood, urine and homogenate glucose concentrations were measured by the glucose oxidase technique. The homogenate samples $(100 \mu 1)$ were diluted in water $(1 \mathrm{ml})$ and $\mathrm{ZnSO}_{4}(0.12 \mathrm{~mol} / 1,0.5 \mathrm{ml})$ and $\mathrm{Ba}(\mathrm{OH})_{2}(0.12 \mathrm{~mol} / 1,0.5 \mathrm{ml})$ added. After centrifugation for $20 \mathrm{~min}$ at $1,500 \mathrm{rev} / \mathrm{min}$, supernatant samples were taken for glucose determination.

Total protein concentrations were measured according to Lowry et al. [9]. Aliquots of homogenates were solubilized first in $0.1 \mathrm{~N}$ $\mathrm{NaOH}$ at $37^{\circ} \mathrm{C}$ for $2 \mathrm{~h}$ and urines were dialyzed against $0.15 \mathrm{~mol} / 1$ $\mathrm{NaCl}$ prior to estimation. Creatinine was determined in urine by the Jaffé reaction [10].

\section{Statistical Methods}

Comparison between diabetic and control groups was by the Student's t-test.

\section{Results}

\section{Characteristics of the Diabetic Rats}

Blood glucose levels after 1,3 and 6 months of diabetes were respectively: $46.5 \pm 1.6$ (mean \pm SEM, $\mathrm{n}=10$ ), $37.7 \pm 1.3$ and $30.2 \pm 1.5 \mathrm{mmol} / \mathrm{l}$ versus $8.4 \pm 0.2,8.2 \pm$ 0.3 and $6.6 \pm 0.3 \mathrm{mmol} / \mathrm{l}$ in the control rats $(n=10)$. Persistant arterial hypertension was observed from day 14 
of diabetes $(23.6 \pm 0.4$ versus $20.5 \pm 0.1 \mathrm{kPa}$ in the controls; $p<0.001)$. Cataracts were present in all diabetic rats after 6 weeks of disease.

At sacrifice, after 33 weeks of diabetes, the following data were noted in the diabetic rats: reduced body weight $(217 \pm 27$ versus $501 \pm 10 \mathrm{~g}$ in the controls, $p<0.001)$; polyuria $(95 \pm 11$ versus $11.7 \pm 1.6 \mathrm{ml} /$ day, $p<0.001)$; elevated creatininuria $(21.4 \pm 1.6$ versus $14.3 \pm 1.1 \mathrm{mg} /$ day, $p<0.005$ ); increased proteinuria ( $38.4 \pm 10$ versus $18.5 \pm 1.7 \mathrm{mg} /$ day, $p<0.05$ ), but protein excretion per mg creatinine was not significantly elevated. Kidney cortex weight was slightly but not significantly increased $(2.59 \pm 0.11$ versus $2.38 \pm 0.11 \mathrm{~g})$. Glucose concentration was similar in the diabetic kidney cortex $(37.5 \pm 2.8 \mathrm{mmol} / \mathrm{kg})$ and plasma $(37.2 \pm 1.4$ $\mathrm{mmol} / \mathrm{l}$ ); it was lower in the normal kidney cortex $(6.81 \pm 0.31 \mathrm{mmol} / \mathrm{kg})$ than in the normal plasma $(9.03$ $\pm 0.23 \mathrm{mmol} / \mathrm{l})$. There was no change in the protein content of the kidney cortex $(155 \pm 6 \mathrm{mg} / \mathrm{g})$ on dialysis.

\section{Enzymatic Determinations}

As shown in Figure 1, Glc-Gal-Hyl glucohydrolase specific activity was increased in the dialyzed kidney cortex homogenate of the diabetic rats. In contrast, the specific activity of the enzyme was decreased in the corresponding non-dialysed fractions. When the glucose concentration was adjusted to the level in vivo, the specific activity was further diminished.

When the enzyme activity was expressed in units per total kidney cortex, similar variations were observed (Fig. 2).

\section{Discussion}

The increase in glucosyl-galactosyl-hydroxylysine glucohydrolase activity in the dialyzed rat kidney cortex previously reported after 19,23 and 28 weeks of diabetes [2] is again confirmed by the measurement of elevated activities after 33 weeks of diabetes induced under similar conditions. In the previous experiments, thickening of kidney glomerular basement membrane was confirmed after 28 weeks of diabetes [2]. The increase in kidney weight observed here, as previously [2], is moderate compared with other published data [11]. The greater severity of the diabetes in our experiments, as reflected by the plasma glucose levels, could account for this.

The most striking result obtained here is that, in the presence of glucose at diabetic concentration in vivo, the glucosyl-galactosyl-hydroxylysine glucohydrolase specific activity is markedly diminished in agreement with our initial hypothesis. This decrease could contribute to glomerular basement membrane thickening since glucosyl-galactosyl-hydroxylysine glucohydrolase is believed to be involved in basement membrane collagen catabolism [1]. This effect would complement those of other enzyme modifications reported in long-term diabetic kidneys: increased activity of lysyl-hydroxylase [12] and glucosyl transferase [13] catalyzing the disaccharide unit synthesis; elevation of prolyl-hydroxylase activity specific for collagen synthesis [12].

In streptozotocin-induced diabetes, blood glucose rises very quickly in the first weeks. Renal cells, unlike adipocytes or muscle cells, appear to be freely permeable to glucose [4]. Glucose concentration has indeed been found to be similar in diabetic plasma and kidney cortex here. Glucose inhibition of glycosyl-galactosylhydroxylysine glucohydrolase activity may therefore contribute to the progressive kidney glomerular basement membrane thickening [15]. In fact basement membrane thickening seems to develop earlier in kidney glomeruli than in muscle [16].

Therefore the increased glucosyl-galactosyl-hydroxylysine glucohydrolase concentration observed in glucose-free kidney cortex homogenates may be a secondary effect related to increase in substrate levels, the primary effect being the inhibition of this enzyme by high glucose levels in vivo.

Acknowledgements. This work was supported by the following institutions: Délégation Générale à la Recherche Scientifique et Technique, Université René Descartes and Faculté de Médecine Broussais - Hôtel-Dieu, Paris. We thank G. Gateau, B. Faure, F. Mège and J. Bourlier for their excellent technical assistance.

\section{References}

1. Sternberg M, Spiro RG (1979) Studies on the catabolism of the hydroxylysine-linked disaccharide units of basement membranes and collagens. Isolation and characterization of a rat kidney $\alpha$ glucosidase of high specificity. J Biol Chem 254: 10329-10336

2. Sternberg M, Grochulski A, Peyroux J, Hirbec G, Poirier J (1982) Studies of the $\alpha$-glucosidase specific for collagen disaccharide units: variations associated with capillary basement membrane thickening in kidney and brain of diabetic and aged rats. Collagen Rel Res 2: 495-506

3. Spiro RG (1969) Characterization and quantitative determination of the hydroxylysine-linked carbohydrate units of several collagens. J Biol Chem 244: 602-612

4. Beisswenger PJ, Spiro RG (1970) Human glomerular basement membrane: chemical alterations in diabetes mellitus. Science 168: 596-598

5. Canivet J, Cruz A, Moreau-Lalande H (1979) Biochemical abnormalities of the human diabetic glomerular basement membrane. Metabolism 28: 1206-1210

6. Taylor SA, Price RG, Kang SS, Yudkin J (1980) Modification of the glomerular basement membrane in sucrose-fed and streptozotocin-diabetic rats. Diabetologia 19: 364-372

7. Sternberg M, André J (1982) Glucose inhibition of the $\alpha$-glucosidase specific for basement membrane and collagen disaccharide units. FEBS Letters 139: 53-56

8. Wahl P, Deppermann D, Deschner W, Fuchs E, Rexroth W (1973) The metabolism of the isolated renal glomerulus and its basement mebranes. In: Camerini-Davalos RA, Cole HS (eds) Vascular and neurologic changes in early diabetes. Academic Press, New York, pp 147-153

9. Lowry HO, Rosebrough NJ, Randall RJ (1951) Protein measurement with Folin phenol reagent. J Biol Chem 193: 265-276 
10. Jaffé M (1886) Über den Niederschlag welchen Pikrinsäure in normalem Harn erzeugt und über eine neue Reaktion des Kreatinins. Hoppe Seyler's Z Physiol Chem 10: 391-400

11. Rasch R (1979) Prevention of diabetic glomerulopathy in streptozotocin diabetic rats by insulin treatment: kidney size and glomerular volume. Diabetologia 16: 126-128

12. Cohen MP, Khalifa A (1977) Effect of diabetes and insulin on rat renal glomerular protocollagen hydroxylase activities. Biochim Biophys Acta 496: 88-94

13. Spiro RG, Spiro M (1971) Effect of diabetes on the biosynthesis of the renal glomerular basement membrane. Studies on the glucosyltransferase. Diabetes 20: 641-648

14. Lubec G, Leban J, Peyroux J, Sternberg M, Pollak A, Latzka U, Coradello H (1982) Reduced collagenolytic activity of rat kidneys with streptozotocin diabetes. Nephron 30: 357-360

15. Farquhar MG, Hopper J Jr, Moon HD (1959) Diabetic glomerulo- sclerosis: electron and light microscopic studies. Am J Path 35: 721-753

16. Cameron DP, Amherdt M, Leuenberger P, Orci L, Stauffacher W (1973) Microvascular alterations in chronically streptozotocindiabetic rats. In: Camerini-Davalos RA, Cole HS (eds) Early diabetes. Advance in metabolic disorders. Academic Press, London, Suppl 2 pp 257-269

Received: 5 May 1982

and in revised form: 2 December 1982

Dr. M. Sternberg,

Département de Biochimie

Faculté de Médecine Broussais

45 rue des Saints-Pères

75270 Paris Cedex 06, France 